\title{
Variações sobre um tema: maneiras de viver das crianças que residem em bairros gentrificados em Paris, Londres e San Francisco
}

\section{Resumo}

Se as relações dos adultos com o bairro estão relativamente bem estudadas pela literatura sobre a gentrificação, não se pode dizer o mesmo a respeito das crianças que, no entanto, constituem uma população muito visível de numerosos bairros gentrificados. Contribuindo para preencher esta lacuna, este artigo analisa as representações, as práticas e as sociabilidades de crianças com idade entre 9 e 11 anos em três bairros gentrificados de Paris, Londres e São Francisco. As análises apresentadas estabelecem que os bairros gentrificados (quando colocam famílias em jogo) são lugares plenamente habitados pelas crianças, que praticam mais a "mistura social" do que seus pais e, de modo mais amplo, do que os adultos que residem nesses bairros. Ao mesmo tempo, o artigo mostra que as maneiras de habitar das crianças nos bairros gentrificados são perpassadas por fortes diferenciações, que derivam em parte dos contextos em que residem e, em parte, das características sociais das crianças (meio social, sexo, idade, posição em relação aos irmãos/irmãs...).

Palavras-chave: Gentrificação. Bairro. Crianças. Diferenciações Sociais. Comparação Internacional.

Variations on a theme: the modes of living of children in gentrified neighborhoods in Paris, London and San Francisco

\section{Abstract}

The gentrification literature has developed a quite extensive knowledge of the neighborhood experience of adult residents. However, the same is not true about

\footnotetext{
* Universidade Lumière Lyon, França.

** Universidade de Paris Ouest Nanterre La Défense, França.
} 
children who are still understudied despite their visibility in many gentrified neighborhoods. This paper is aimed to fill this gap by examining the discourse, practice and sociability of children aged 9 to 11 in three gentrified neighborhoods of Paris, London and San Francisco. The analyses show that gentrified neighborhoods (when families are in play) are fully occupied by children, and that they are more exposed to "social diversity" than their parents and, more broadly, than the adults who live in these neighborhoods. Simultaneously the paper shows that the children's ways of living and of co-existing in gentrified neighborhoods are marked by important differences. This results partly from their residential geographies and partly from their own social characteristics (social class, gender, age, position within the siblings...).

Keywords: Gentrification. Neighborhood. Children. Social Differentiation. International Comparison.

\section{Variations sur un thème : les manières d'habiter des enfants dans les quartiers gentrifiés à Paris, Londres et San Francisco}

\section{Résumé}

Si les rapports au quartier des adultes sont relativement bien étudiés par la littérature sur la gentrification, on ne peut pas en dire autant en ce qui concerne les enfants, qui, pourtant, constituent une population très visible de nombreux quartiers gentrifiés. Pour contribuer à combler cette lacune, cet article examine les représentations, les pratiques et les sociabilités d'enfants âgés de 9 à 11 ans dans trois quartiers gentrifiés de Paris, Londres et San Francisco. Les analyses présentées établissent que les quartiers gentrifiés (lorsqu'ils mettent en jeu des familles) sont des lieux pleinement habités par les enfants, qui pratiquent davantage « la mixité sociale » que leurs parents et, plus généralement, que les adultes qui résident dans ces quartiers. En même temps, l'article montre que les manières d'habiter et de cohabiter des enfants, dans les quartiers gentrifiés, sont traversées par de fortes différenciations, qui tiennent pour partie aux contextes dans lesquels ils résident, et pour partie aux caractéristiques sociales des enfants (milieu social, sexe, âge, position dans la fratrie...).

Mots-clés: Gentrification. Quartier. Enfants. Différenciations sociales. Comparaison internationale.

\footnotetext{
-Texto traduzido por Cláudia Maia e Valéria Milena R. Ferreira e com revisões técnicas de Márcio Sérgio B. S. de Oliveira e de Regina Vargas.

Publicado em francês originalmente em Métropoles [online], no $11 \mid 2012<\mathrm{http} / /$ metropoles.revues.org/4584>
} 


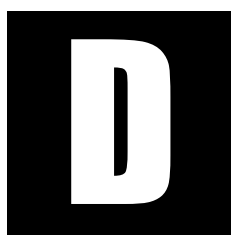

esde o estudo pioneiro de Ruth Glass em 1960, consagrado à renovação social de um antigo bairro popular do centro de Londres invadido por famílias pertencentes às camadas médias e altas (Glass, 1964), a gentrificação foi o tema de uma extensa literatura (Atkinson; Bridge, 2005; Lees et al., 2008; Authier; Bidou-Zachariasen, 2008). Mas, como salientou recentemente Anne Clerval, "o lugar das famílias e das crianças na gentrificação foi [...] pouco abordado até aqui" (Clerval, 2008, p. 43) 1 .

Quando isso ocorreu, os autores se concentraram principalmente em analisar as estratégias escolares das famílias de classes médias, que constituem um bom indicador da sua relação com a "mistura social", tanto dentro de pesquisas diretamente centradas na gentrificação (Butler, 2003; Butler; Robson, 2003; Clerval, 2008; Collet, 2010), como no âmbito de trabalhos voltados mais amplamente para as escolhas educacionais das classes médias (Oberti, 2007; Van Zanten, 2009).

Em uma perspectiva relativamente próxima, outros pesquisadores, menos numerosos, exploraram as escolhas relacionadas aos cuidados na primeira infância, feitas por pais pertencentes às classes médias de bairros gentrificados (Ball et al., 2004). Enfim, alguns autores estudaram as escolhas residenciais de famílias de classes médias que, ao invés de se instalarem em bairros distantes, como é geralmente o caso, preferiram mudar-se e criar seus filhos em bairros gentrificados no centro das cidades (Karsten, 2003; 2007). Nesse conjunto relativamente limitado de trabaIhos, os pesquisadores concentraram seu olhar mais sobre as famílias de classes médias do que naquelas de meios populares. Mais ainda, nessas pesquisas, os autores se interessaram mais pelos pais do que pelas crianças, a partir de investigações realizadas exclusivamente junto aos adultos.

\footnotetext{
${ }^{1}$ A gentrificação, na verdade, não é sempre um assunto de famílias e de crianças. Em certos contextos, ela é mais o feito de pessoas sozinhas ou jovens casais sem filhos. (Dansereau, 1985; Van Criekingen, 2008). No entanto, muitas situações de gentrificação colocam em jogo agregados familiares.
} 
Também esses trabalhos trazem, no total, razoavelmente poucos elementos de conhecimento sobre as maneiras de habitar das crianças, de diferentes meios sociais, que residem nos bairros gentrificados e sobre suas maneiras de coabitar além dos muros da escola. E, no entanto, as crianças também são moradoras desses bairros, portadoras de práticas e relações sociais que podem ter efeitos de feedback sobre as maneiras de viver de seus pais. Além disso, suas práticas e sociabilidades locais, porque são mais ou menos definidas por seus pais, constituem igualmente um bom indicador das relações que seus pais mantêm com a "mistura social" nos bairros gentrificados.

Esse fraco interesse pelas crianças e suas maneiras de habitar não é peculiar à literatura sobre a gentrificação. Nas ciências sociais francófonas, existem, de fato, relativamente poucos trabalhos sobre as crianças antes da adolescência (Sirota, 2006) e, em particular, muito poucos estudos sobre as práticas urbanas das crianças:

a maioria das pesquisas fora da esfera privada se interessa por outras instituições além da família - a creche, os conselhos municipais de crianças, a escola, os centros de lazer $[. .$.$] e poucos trabalhos dizem respeito a crianças com$ menos de 12 anos na esfera pública estritamente falando. (Danic et al., 2006, p. 82).

Embora alguns estudos pioneiros tenham aberto caminho às pesquisas sobre as práticas das crianças na cidade e sobre suas percepções dos espaços urbanos (Casabianca, 1959; Frémont, 1976; Chombart de Lauwe, 1977), esse campo de pesquisa, por muito tempo, permaneceu relativamente marginal na França e nos países francófonos. Nos últimos anos, alguns trabalhos sobre essas temáticas surgiram, mas tratam-se principalmente ou de trabalhos sobre "as crianças da rua" (Tessier, 2005; Morelle, 2007), ou de trabalhos de psicólogos (associados por vezes a geógrafos) que analisam as modalidades de desenvolvimento das competências espaciais das crianças em uma perspectiva cognitivista (Ramadier; Depe- 
au, 2010; Enaux; Legendre, 2010), ou que estudam a maneira pela qual os conhecimentos do espaço (urbano) das crianças se articulam com suas práticas, suas mobilidades e sua autonomia de deslocamento (Depeau, 2003; 2008; Tsoukala, 2007; Legendre, 2010). No campo da sociologia urbana, as poucas produções contemporâneas que fazem referência às crianças contentam-se em indicar, de modo muito geral, que o território privilegiado das jovens crianças na cidade é o bairro (de residência), ao contrário dos habitantes adultos (Ascher, 1995).

O fraco número das pesquisas francófonas sobre as crianças e a cidade contrasta com a vitalidade desse campo na literatura anglófona ${ }^{2}$. Depois de alguns precursores (Lynch, 1977; Ward, 1978; Hart, 1979), numerosos pesquisadores valendo-se dos Children's Studies inclinaram-se, a partir dos anos 1990, sobre as práticas diárias das crianças nas cidades e revelaram quatro tendências concomitantes: mostraram o declínio de sua presença nos espaços públicos, sua perda de autonomia espacial, a institucionalização de suas atividades e a fragmentação de suas práticas (Holloway; Valentine, 2000; Chawla, 2002; Christensen; O'Brien, 2003; Valentine, 2004). Ao mesmo tempo, recusando a ideia de criança universal, eles reconheceram a importância das diferenciações sociais e residenciais na estrutura dos territórios das crianças. No entanto, são poucos os trabalhos diretamente centrados sobre essa questão (Karsten, 2005; Nordström, 2010) e mais raros ainda são os estudos que comparam crianças residindo em vários bairros do mesmo tipo, ou examinando, em um determinado bairro, as diferentes maneiras de habitar e coabitar das crianças.

Nesse contexto, este artigo se propõe a estudar as maneiras de viver e de conviver das crianças - e suas variações - nos bairros gentrificados, questionando os efeitos do contexto residencial e das características sociais das crianças. Ele se baseia em uma pesquisa realizada em três bairros gentrificados de Paris (Batignolles), Londres (Stoke Newington) e

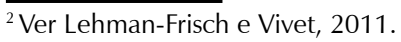


São Francisco (Noe Valley) ${ }^{3}$, cujo objetivo geral era estudar as relações de coabitação que se instauram nos bairros gentrificados entre as famílias "gentrificadoras" (de classes médias ou médias-altas) e as famílias "gentrificadas" (de classes populares), por meio das crianças ${ }^{4}$. Trata-se de analisar como as crianças são levadas em conta nas escolhas residenciais dos habitantes desses bairros, de estudar como as crianças intervêm nas maneiras de habitar e de coabitar das famílias "gentrificadoras" e das famílias "gentrificadas", mas igualmente de observar as maneiras de viver e de conviver das próprias crianças. Nessa perspectiva, e a fim de distinguir ao mesmo tempo tendências comuns e diferenciações "locais", escolhemos trabalhar sobre três grandes cidades onde os processos de gentrificação são bem documentados (Lehman-Frisch, 2002; Butler; Robson, 2003; Clerval, 2008) e cujas respectivas municipalidades recentemente apontaram a questão das crianças (de seu declínio numérico e das desigualdades crescentes que as afligem) como uma de suas maiores preocupações. Dentro dessas três cidades, os bairros selecionados têm todos um passado solidamente popular e atravessaram, igualmente, uma fase de declínio socioespacial antes de serem procurados pelas camadas médias e médias-altas, a partir de 1980 e, sobretudo, 1990. São também, todos os três bairros, identificados pelos moradores como "muito familiares", onde as crianças estão sobrerrepresentadas em relação às cidades nas quais se inscrevem. No interior desses bairros, o trabalho de pesquisa tomou a forma de investigação ao mesmo tempo junto aos adultos e junto às crianças.

Neste artigo, utilizaremos exclusivamente os materiais derivados das entrevistas que realizamos com essas crianças (ver o anexo metodológico). Em um primeiro momento, proporemos uma visão geral das relações simbólicas e efetivas que as crianças pesquisadas mantêm com os três

\footnotetext{
${ }^{3}$ Ver os mapas localizados no final do anexo metodológico.

${ }^{4}$ Essa pesquisa foi financiada pelo Fundo Nacional dos Abonos Familiares e realizada em colaboração com Frédéric Dufaux (Universidade de Paris-Ouest).
} 
bairros observados. Mostraremos, em seguida, que as maneiras de habitar das crianças nos bairros gentrificados são atravessadas por fortes diferenciações que derivam, em parte, dos contextos nos quais elas residem e, em parte, das características sociais próprias das crianças (meio social, sexo, idade etc.). Com base nessas análises, distinguiremos então "vidas de bairro" muito discrepantes que, ao mesmo, tempo resultam e fazem parte da diferenciação social dessas crianças.

\section{Espaços "vivenciados"... sob vigilância}

Em sintonia com apego consensual dos adultos para com os bairros gentrificados, frequentemente mostrados pelos trabalhos sobre gentrificação (Ley, 1996; Authier, 2001; Butler, Robson, 2003), uma grande maioria das crianças entrevistadas afirmou apreciar os bairros gentrificados. Se eles são muito apreciados, são também em geral bem conhecidos das crianças: $60,7 \%$ delas reconheceram o conjunto dos lugares representados pelas fotografias enquanto, ao contrário, apenas $11,4 \%$ das crianças têm um fraco conhecimento do bairro. Mas o grau de conhecimento do bairro não é uniforme entre as crianças, longe disso. Assim, as crianças que moram no bairro são proporcionalmente mais numerosas entre as que o conhecem bem, do que aquelas que moram em outros lugares; contudo, mais de metade dessas últimas estão muito familiarizadas com os lugares. Associado à localização da habitação, mas não totalmente determinado por ela, o modo de deslocamento do domicílio para a escola também intervém no conhecimento do bairro: as crianças que vão a pé para a escola (sempre ou por vezes) têm um melhor conhecimento dos bairros da pesquisa do que aquelas que vão para a escola exclusivamente de carro e/ou de transporte comum. Por outro lado, o meio social desempenha um papel muito claro: quanto mais as crianças são vindas de meios 
sociais abastados, melhor é o seu conhecimento do bairro. Da mesma maneira, os meninos demonstram conhecer mais o bairro do que as meninas. Portanto, o conhecimento do bairro varia claramente em função das diferenciações sociais das crianças e é a partir de suas vivências no bairro que essas variações fazem sentido.

Quadro 4. Os usos do bairro gentrificado

\begin{tabular}{|l|c|c|c|c|c|}
\hline & $\begin{array}{c}\text { Muito } \\
\text { Frequentemente }\end{array}$ & Frequentemente & Raramente & Nunca & Total \\
\hline $\begin{array}{l}\text { O uso dos } \\
\text { parques } \\
\text { e jardins } \\
\text { públicos }\end{array}$ & 28,3 & 38,3 & 30,8 & 2,5 & 100 \\
\hline $\begin{array}{l}\text { O uso do } \\
\text { comércio }\end{array}$ & 15,8 & 43,3 & 30,0 & 10,8 & 100 \\
\hline $\begin{array}{l}\text { O uso das } \\
\text { bibliotecas }\end{array}$ & 16,7 & 37,5 & 24,2 & 21,7 & 100 \\
\hline $\begin{array}{c}\text { As } \\
\text { atividades } \\
\text { praticadas }\end{array}$ & $\begin{array}{c}\text { Atividades } \\
\text { na escola }\end{array}$ & $\begin{array}{c}\text { Atividades fora } \\
\text { da escola }\end{array}$ & Os dois & $\begin{array}{c}\text { Sem } \\
\text { atividade }\end{array}$ & Total \\
\hline & 32,7 & 37,3 & 18,2 & 11,8 & 100 \\
\hline $\begin{array}{l}\text { Índice de } \\
\text { uso do } \\
\text { bairro }\end{array}$ & $\begin{array}{l}\text { Uso muito forte } \\
(\mathrm{N}=4)\end{array}$ & $\begin{array}{c}\text { Uso forte } \\
(\mathrm{N}=3)\end{array}$ & $\begin{array}{l}\text { limitado } \\
(\mathrm{N}=2)\end{array}$ & $\begin{array}{l}\text { Fraco uso } \\
(\mathrm{N}=0 / 1)\end{array}$ & Total \\
\hline & 32,1 & 23,6 & 27,4 & 17,0 & 100 \\
\hline
\end{tabular}

Fonte: Elaborado pelos autores.

Nota: todos os valores mencionados correspondem a porcentagens; o índice de uso do bairro contabiliza o número de práticas efetuadas muito frequentemente ou frequentemente (para o uso de parques, comércio e bibliotecas) além do fato de praticarem ou não atividades extraescolares (na escola e/ou fora da escola). 
Se as crianças apreciam os bairros gentrificados e se elas os conhecem bem, é porque elas têm um uso intensivo dos mesmos. Então, grande número delas acumula diversos tipos de práticas (o uso do comércio, dos parques ou das bibliotecas, ou ainda a prática de atividades extraescolares), como mede o índice de uso do bairro (cf. quadro 4). Um terço dessas crianças acumula ainda o conjunto desses usos e ao contrário, apenas uma minoria tem um uso fraco do bairro, praticando apenas uma ou mesmo nenhuma dessas atividades. O bairro não se reduz assim, a um mero cenário para a maioria dessas crianças.

Esses fortes usos se apoiam, antes de tudo, sobre as atividades extraescolares praticadas no bairro, que dizem respeito a mais de quatro quintos das crianças pesquisadas. Essas atividades, que consistem em atividades esportivas, culturais ou religiosas e que podem ser ou não institucionalizadas, se desenrolam, para alguns, no interior da escola (mas fora do tempo escolar, a exemplo dos "Ateliês azuis", fornecidos pela prefeitura de Paris ${ }^{5}$ ), para outros, em outras partes do bairro, enquanto perto de um quinto das crianças acumula os dois registros. Esse resultado testemunha forte desenvolvimento das atividades extraescolares nos países desenvolvidos, como mostram vários outros trabalhos (Lareau, 2003; Sautory et al., 2011). Ele também atesta sua importância na construção da relação das crianças com o bairro, na medida em que essas atividades suscitam deslocamentos (a pé ou motorizados) e desenvolvem sociabilidades ancoradas localmente. Os parques e os jardins são, em seguida, os lugares mais frequentados pelo conjunto das crianças (dois terços delas os visitam "muito frequentemente" ou "frequentemente" e apenas três crianças "nunca" vão a esses lugares). Por isso, eles se constituem em polos importantes da socialização local das crianças e passam a ser

$\overline{{ }^{5} \text { Os "Ateliês azuis" }}$ propõem atividades culturais, científicas ou esportivas depois da escola (de $16 \mathrm{~h} 30$ às 18h). O objetivo desses ateliês é permitir às crianças descobrirem disciplinas que elas não têm a oportunidade de praticar regularmente no âmbito escolar. 
verdadeiros espaços partilhados. Uma forte proporção das crianças utiliza igualmente "frequentemente" ou "muito frequentemente" o comércio dos bairros gentrificados, reforçando a ideia de que as ruas comerciais dos bairros gentrificados ocupam, para as crianças como para os adultos (Bridge; Dowling, 2001; Lehman-Frisch, 2002), um lugar privilegiado nas práticas locais. Finalmente, embora menos que os parques e jardins e também o comércio, a biblioteca não deixa de ser um lugar utilizado "muito frequentemente" ou "frequentemente" por mais da metade das crianças.

No entanto, as crianças pesquisadas não desdobram livremente suas práticas no interior dos bairros gentrificados. Ao contrário, para dois terços delas, seus usos são "fortemente" ou "muito fortemente" enquadrados por seus pais, que as acompanham (ou asseguram que elas sejam acompanhadas) durante seus deslocamentos, e não as deixam frequentar sozinhas os parques, o comércio ou a biblioteca. Em particular, 58\% das crianças vão para a escola (ou retornam da escola) sempre acompanhadas por seus pais ou por outros adultos e, inversamente, apenas $17,8 \%$ das crianças fazem sistematicamente seus trajetos sozinhas, confirmando os resultados de pesquisas recentes sobre o forte monitoramento dos trajetos escolares das crianças na escola primária (Sautory et al., 2011). O uso intenso pelas crianças dos bairros gentrificados faz-se, portanto, sob a vigilância atenta de seus pais.

Ao mesmo tempo, esses bairros gentrificados não constituem os únicos lugares de vida das crianças pesquisadas. Certamente, aquelas que não moram nesses bairros desenvolvem certo número de práticas e atividades em seu bairro de residência, mas aquelas que moram neles também atestam atividades fora dos bairros gentrificados. No total, são muitas a fazer passeios culturais e de lazer (50,5\%), a visitar sua família ou amigos (46,7 \%), a frequentar parques ou jardins (45,7\%), a fazer compras (44,8\%), ou mesmo a praticar atividades esportivas ou artísticas $(32,4 \%)$ e, 
para alguns, a acumular uma ou mais dessas atividades, fora do seu bairro de residência. Se o que as crianças fazem fora do seu bairro contribui para estruturar seus usos no interior do bairro, como nós analisamos em outro momento (Authier; Lehman-Frisch, 2013), a continuação desse artigo se concentra sobre as práticas no interior dos bairros de pesquisa.

Assim, as crianças pesquisadas "habitam" plenamente os bairros gentrificados: elas exprimem, no conjunto, uma representação positiva, um conhecimento detalhado e usos intensivos. Mas suas maneiras de habitar, que são largamente supervisionadas por seus pais, são também atravessadas por nítidas diferenciações que derivam, em parte, de seus contextos residenciais e, em parte, de suas características sociais.

\section{Relações com os bairros e efeitos de lugares}

A relação das crianças com os bairros gentrificados varia sensivelmente em função de seu contexto residencial, observado em diferentes escalas. Dependendo de seu domicílio estar localizado dentro ou fora desses bairros, de residirem a uma maior ou menor distância da escola, enfim, dependendo de residirem em Paris, Londres ou São Francisco, discernimos diferenças nítidas em seus usos dos bairros.

As crianças pesquisadas utilizam diariamente os bairros gentrificados, mas somente a metade delas reside nesses bairros, a outra metade mora fora dos limites dos bairros de estudo. Logicamente, essa característica residencial tem uma forte influência sobre os usos que elas fazem. Assim, as que moram no bairro gentrificado revelam usos mais intensos e diversificados (73,6\% das crianças têm um índice de uso do bairro "forte" ou "muito forte") em comparação com as crianças que vivem em outros lugares $(37,7 \%)$. O desvio concernente à intensidade de uso das primeiras em relação às segundas é particularmente acentuado para os parques 
e o comércio, e secundariamente, para as bibliotecas, enquanto a diferença envolvendo as atividades extracurriculares praticadas no bairro é claramente menos importante. Ao contrário, as crianças que moram fora do bairro têm mais tendência do que as outras de praticar essas atividades no interior da escola, enquanto as que moram no bairro têm atividades mais frequentes fora da escola ou acumulam atividades dentro e fora do recinto escolar.

Na mesma perspectiva, mas em uma escala mais precisa, observa-se uma forte correspondência entre a distância domicílio/escola ${ }^{6}$ e a intensidade dos usos. De maneira geral, quanto mais as crianças moram perto da escola, mais elas apresentam usos intensos e variados do bairro gentrificado, seguindo uma correlação linear. Sem surpresa, com o distanciamento geográfico, os pais reforçam o enquadramento dos usos de seus filhos, com um limiar muito claro de dois quilômetros: as crianças que vivem além desse limite são mais tendentes a ser fortemente ou muito fortemente enquadradas do que as crianças que moram mais perto. Na medida em que morem a mais de um quilômetro da escola, as crianças são, também, bem menos suscetíveis a efetuarem a pé seu trajeto até a escola (caso de $31,1 \%$ entre elas, contra $90,4 \%$ para as crianças que moram mais perto), e a fazê-lo "sempre ou por vezes sozinhas" (20,7 \% contra 66,6 \%). No total, conforme esses resultados, o enquadramento é menos frequentemente "forte" ou "muito forte" para as crianças que moram nos bairros gentrificados do que para as outras.

Em uma escala menor, Batignolles, Stoke Newington e Noe Valley são muito diversamente utilizados pelas crianças pesquisadas. A influência da localização do domicílio tem sua parte na explicação dessas variações: enquanto mais da metade das crianças pesquisadas em Batignolles e em Stoke Newington mora no bairro gentrificado, o mesmo ocorre para

\footnotetext{
${ }^{6}$ Todas as escolas selecionadas estão situadas no coração dos bairros gentrificados, perto de sua
} principal rua comercial, de uma biblioteca e de um parque. 
apenas cerca de um terço das crianças pesquisadas em Noe Valley. Mas, além desse fator, emergem certas diferenças de uso, que parecem mais diretamente ligadas à especificidade de cada contexto urbano. Assim, as crianças de Stoke Newington apresentam maior tendência a ocupar o bairro gentrificado: mais da metade delas conjuga o uso do comércio, dos parques, das bibliotecas e de atividades, enquanto isso acontece para apenas uma criança em cinco, em Noe Valley, e uma criança em seis, em Batignolles.

Para os três bairros, o uso local pelas crianças repousa, primeiramente, sobre as atividades extraescolares. Mas, em Noe Valley e em Stoke Newington, esse uso diz respeito a uma proporção bem maior de crianças (perto de 95\% nos dois casos) do que em Batignoles (78\%): apesar de um desenvolvimento geral das atividades extraescolares nos países ocidentais, desde os anos 1990 (Wimer et al., 2006; Ananian; Bauer, 2007; Sautory et al., 2011), as crianças parecem, portanto, menos sistematicamente envolvidas em atividades extraescolares na França do que nos Estados Unidos ou no Reino Unido - fato, sem dúvida, relacionado à sua jornada escolar mais longa. O segundo principal uso registrado, os parques e os jardins dos bairros gentrificados, é mais frequente entre as crianças de Stoke Newington e de Batignolles do que entre as de Noe Valley. No bairro gentrificado de São Francisco, alguns elementos, como o tamanho reduzido e a localização descentralizada dos parques em relação ao coração do bairro, assim como a forte dispersão residencial das crianças pesquisadas dentro e fora do bairro, ou ainda a presença de muitos quintais associados às habitações, contribuem a explicar esse resultado. Ao contrário, o Clissold Park, em Stoke Newington, e o Parque Cardinet, em Batignolles, são parques relativamente grandes, situados próximos ao coração do bairro e aparecem como espaços públicos locais fortemente apropriados e amplamente partilhados. Se as crianças de Noe Valley uti- 
lizam menos frequentemente os parques locais, elas são mais tendentes a frequentar o comércio do bairro - de acordo com o que havia sido observado junto aos adultos que vivem nesse bairro (Lehman-Frisch, 2002) - do que as crianças de Stoke Newington e, sobretudo, de Batignolles. Além disso, o uso da biblioteca é mais favorecido pelas crianças de Stoke Newington do que por aquelas de Noe Valley ou de Batignolles.

Esses usos são supervisionados de modo muito diverso, conforme o bairro. A proporção de crianças "(muito) fortemente" monitoradas é maior em Noe Valley $(89,6 \%)$ do que em Batignolles $(64,7 \%)$ e a diferença é ainda mais acentuada em relação a Stoke Newington (44,7 \%). Esse resultado se explica, em parte, pela mais forte dispersão das crianças pesquisadas em Noe Valley (dentro e fora do bairro de estudo), que provoca uma forte motorização dos deslocamentos, como confirmado pela fraca proporção de crianças que vão à escola a pé: o conjunto de seus usos do bairro gentrificado é assim mais frequentemente acompanhado por adultos.

No total, as relações das crianças com o bairro são nitidamente definidas ao mesmo tempo por efeitos de localização e de lugares. No entanto, a geografia não explica tudo. Trata-se, a partir de agora, de mostrar em que medida a proximidade ou a distância social influencia também as diferenciações dos usos dos bairros gentrificados pelas crianças.

\section{Maneiras de viver socialmente diferenciadas}

As crianças escolarizadas na escola pública (incluindo a escola confessional de Stoke Newington) e aquelas escolarizadas nas escolas privadas vivenciam diferentemente os bairros observados. As primeiras utilizam mais frequentemente as lojas, as bibliotecas e os parques do que as segundas e se caracterizam, mais globalmente, por um índice de uso do 
bairro mais elevado. Além disso, as primeiras são muito menos supervisionadas por seus pais em suas maneiras de vivenciar o bairro do que as segundas. Essas diferenças podem, sem dúvida, se explicar, mais uma vez e em parte, por um "efeito de lugar", conduzindo as crianças escolarizadas em tal ou tal escola a terem práticas relativamente similares. Elas derivam também, certamente, do fato de que os pais das crianças escolarizadas na escola pública não têm as mesmas lógicas educativas que os pais das crianças escolarizadas na escola privada. Mas, por trás dessas diferenças entre as crianças da escola pública e da privada, residem também diferenças em termos de meios sociais.

Pois as escolas situadas em Batignolles, Noe Valley e Stoke Newington não acolhem somente crianças que moram nesses três bairros; algumas famílias de classes médias ou de classes médias-altas morando nesses bairros evitam para seus filhos os estabelecimentos escolares públicos (muito "mistos") situados próximos ao seu domicílio; e também, porque as famílias (de classes médias ou de classes médias-altas) que moram nesses bairros não são todas famílias com filhos (ou com filhos em idade de serem escolarizadas nas escolas primárias); a composição de nossa população de crianças é socialmente muito mais diversificada do que a população desses três bairros gentrificados. Assim, se as crianças de classes médias-altas (26,3\%) e as crianças de classes médias (30,5\%) constituem a maioria da nossa amostra, as crianças de classes populares constituem a categoria mais numerosa $(43,2 \%)^{7}$.

Essas três categorias de crianças não habitam da mesma maneira os bairros gentrificados. As crianças de classes médias-altas são as mais propensas a ter "um uso muito forte" dos bairros pesquisados (37\% contra $30 \%$ para o conjunto das crianças). Elas são particularmente as mais numerosas a praticar localmente atividades extraescolares, e a acumular

${ }^{7} \mathrm{O}$ que tende a confirmar a ideia de que a gentrificação agiria sobre o espaço escolar com certo lapso de tempo em relação ao espaço social urbano (Clerval, 2008, p. 403). 
tais atividades no interior da escola e em outras partes do bairro, e as mais numerosas a utilizar muito frequentemente ou frequentemente as lojas. Ao contrário do que se poderia ter esperado ${ }^{8}$, as crianças de classes populares têm também tendência a "vivenciar" plenamente os três bairros: entre elas, mais de uma criança em cada três se caracteriza por um "uso muito forte" do bairro, e mais de uma criança em cada quatro por um "forte uso". Essa tendência, mais marcada para as crianças de classes populares para quem o bairro gentrificado é o bairro de residência, constitui, talvez em parte, um efeito da gentrificação, indo na direção de uma relativa uniformização, nos bairros gentrificados, dos modos de habitar das crianças das classes populares e dos modos de habitar das crianças de classes altas que elas encontram regularmente.

Ao mesmo tempo, as crianças de classes populares não fazem exatamente os mesmos usos dos bairros pesquisados em comparação com as crianças de classes médias-altas. As primeiras são, assim, proporcionalmente muito menos tendentes a praticar atividades extraescolares nos bairros da pesquisa (particularmente fora da escola), e menos tendentes igualmente a utilizar muito frequentemente ou frequentemente as lojas. Inversamente, elas frequentam mais maciçamente os parques e os jardins públicos, mas também as bibliotecas. Este último resultado, em contradição aparente com os trabalhos que enfatizam as fortes ligações entre capital cultural e práticas culturais (Bourdieu, 1979) pode, sem dúvida, explicar em grande parte dois fenômenos distintos identificados durante as entrevistas realizadas junto às crianças: de um lado, algumas crianças de classes médias-altas, que dispõem de uma biblioteca em casa, não necessitam frequentar bibliotecas públicas para realizar suas práticas de leitura, o que confirma a tendência desses grupos sociais à mercantilização

${ }^{8} \mathrm{~A}$ maioria das pesquisas enfatiza, de fato, o movimento de desapropriação (simbólico e prático) que arrebata os adultos vindos das classes populares nos bairros gentrificados (Clerval, 2008; Lehman-Frisch, 2002). 
e à privatização do acesso aos equipamentos (McNeal, 1992; McKendrick et al., 2000); por outro lado, algumas crianças de classes populares frequentam as bibliotecas públicas não somente para emprestar livros, mas também, e por vezes, principalmente, para usar equipamentos informáticos que elas não têm em casa.

Enfim, ao contrário desses dois grupos de crianças, as crianças de classes médias se distinguem por um uso muito mais limitado dos bairros gentrificados ${ }^{9}$ : elas são, por exemplo, proporcionalmente mais tendentes a não frequentar ou frequentar raramente as bibliotecas e as mais tendentes a não frequentar os parques e os jardins públicos ou a fazê-lo raramente. Sua relação mais distanciada em relação ao bairro gentrificado e, particularmente, aos lugares antes citados, que são, ao contrário, intensamente ocupados pelas crianças de classes populares, sem dúvida, deriva em parte de sua posição social "intermediária" entre as crianças de classes médias-altas e as crianças de classes populares. Efetivamente, e para dizê-lo em poucas palavras, pelo fato de que viver nesses bairros gentrificados é também partilhá-lo com crianças de diferentes meios sociais; e porque a distância social entre as crianças de classes médias e as de classes populares é menos evidente do que a que separa as crianças de classes médias-altas das de classes populares, as crianças de classes médias dificilmente convivem ou estão autorizadas por seus pais a conviver com crianças de classes populares ${ }^{10}$.

\footnotetext{
${ }^{9} 43,8 \%$ dessas crianças têm "um uso limitado" e 15,6\% um "uso fraco".

${ }^{10}$ De fato, como já enfatizamos em outro lugar, a partir da comparação dos trabalhos conduzidos junto aos adultos que vivem em diferentes contextos de "mistura social", "para que relações sociais possam se instaurar entre diferentes populações que compartilham um mesmo espaço residencial, parece necessário que as diferenças entre as populações sejam inequívocas, e que uma inversão de situação pareça impossível. Em outros termos, quando a distância social é inequívoca, quando o jogo das demarcações é desnecessário, quando não há risco de confusão e de humilhações, então relações de sociabilidade entre os diferentes componentes são possíveis" (Authier, 2008, p. 111-2).
} 
O peso do meio social das crianças não influencia apenas a intensidade e a natureza do uso dos bairros gentrificados. Ele intervém também, com força, na supervisão desses usos (pelos pais, por um avô, por uma baby-sitter etc.). Aqui, como em alguns outros contextos (Lareau, 2003), o contraste entre as crianças de classes médias-altas e as crianças de classes populares é muito marcado: em geral, os usos do bairros gentrificado pelas crianças de classes médias-altas são frequentemente muito fortemente monitorados: ao contrário, as crianças de classes populares se caracterizam, frequentemente, por usos bem mais autônomos (cf. quadro 5).

Quadro 5. A supervisão dos usos do bairro pesquisado segundo o meio social das crianças

\begin{tabular}{|l|l|l|l|l|}
\hline & Muito forte & \multicolumn{1}{|c|}{ Forte } & \multicolumn{1}{|c|}{$\begin{array}{c}\text { Flexível ou muito } \\
\text { flexível }\end{array}$} & Total \\
\hline Classes médias-altas & $46,7 \%$ & $33,3 \%$ & $20,0 \%$ & 100 \\
\hline Classes médias & $30,3 \%$ & $33,3 \%$ & $36,4 \%$ & 100 \\
\hline Classes populares & $17,1 \%$ & $41,5 \%$ & $41,5 \%$ & 100 \\
\hline Total & $29,8 \%$ & $36,5 \%$ & $33,7 \%$ & 100 \\
\hline
\end{tabular}

Fonte: Elaborado pelos autores.

Além disso, as crianças de classes médias-altas e as crianças de meios populares (e particularmente, nos dois casos, aquelas para quem o bairro gentrificado é também o bairro de residência) se distinguem em relação às atividades que praticam fora dos bairros de pesquisa. Efetivamente, as primeiras têm, muito mais frequentemente do que as segundas, tendência a praticar (também) atividades (esportivas, artísticas e culturais) fora dos três bairros gentrificados selecionados. Em outras palavras, as crianças de classes médias-altas "ocupam" fortemente os bairros gentrificados. No entanto, seus usos desses bairros são muito supervisionados e acompanhados de diversas práticas fora dos mesmos. Por sua vez, as crianças das classes populares e, particularmente, aquelas que habitam nesses bairros 
gentrificados fazem, igualmente, vários usos desses bairros, mas que são ao mesmo tempo menos monitorados e mais exclusivos. Por fim, as crianças das classes médias caracterizam-se por uma relação mais distanciada com os bairros gentrificados e por usos desses bairros cuja supervisão é muito mais diversa.

\section{Uma história de criança e um assunto de família}

O meio social não é o único elemento que molda as relações das crianças com os bairros gentrificados. O seu sexo e a sua idade, mas igualmente a configuração familiar na qual elas estão inseridas, participam também da estruturação de suas maneiras de habitar nesses bairros, de modo diferenciado segundo os meios sociais.

\section{Os bairros das meninas e os bairros dos meninos}

Em geral, meninas e meninos não se distinguem no nível do uso do bairro, mas isso não significa que as crianças vivenciem o bairro da mesma maneira. Mais precisamente, se elas frequentam em proporções muito semelhantes as lojas e as bibliotecas, elas não fazem o mesmo uso dos parques e dos jardins públicos e não participam de forma idêntica das atividades extraescolares propostas localmente, nos estabelecimentos escolares ou em outros lugares no bairro. Os meninos têm, assim, maior tendência a frequentar os parques e os jardins públicos do que as meninas. Inversamente, há uma maior proporção de meninas a praticar atividades extraescolares e o fazem mais nos estabelecimentos escolares do que em outros lugares no bairro. Em outras palavras, a relação das meninas com os bairros gentrificados mostra-se mais institucionalizada do que a dos meninos. Ela é também, e isso vai no mesmo sentido, muito mais supervisionada pelos pais. No grupo pesquisado, mais de três quar- 
tos das meninas é "muito fortemente" ou "fortemente" monitorada nos usos que fazem desses bairros, por seus pais, que as acompanham ao parque, à biblioteca, à suas atividades extraescolares etc. Ao contrário, nesse mesmo registro, mais da metade dos meninos aproveita-se de um monitoramento "flexível" ou "muito flexível". Esse controle social (pelas instituições, pelos pais), fortemente sexuado, das maneiras de habitar os bairros pesquisados, que não é exclusivo dos bairros gentrificados (Valentine, 2004), se observa no acompanhamento do trajeto domicílio-escola: predominam as meninas entre as crianças que fazem esse trajeto sempre acompanhadas por seus pais e, ao contrário, os meninos estão sobrerrepresentados entre as que fazem esse trajeto sempre sozinhas.

Uma relação com o bairro que diminui com o aumento da idade

Em nossa amostra, as diferenças de idade entre as crianças não são muito elevadas (dois anos separam as crianças mais novas, com idade de 9 anos no momento da pesquisa, das crianças mais velhas), mas a consideração desta característica permite identificar uma tendência sensível: as relações das crianças com os bairros gentrificados diminuem com o avanço da idade. As crianças mais novas estão em maior proporção entre as que acumulam os quatro registros de práticas. Ao contrário, as crianças com idade de 11 anos são as mais propensas a ter um "fraco uso" dos bairros estudados, e as crianças de 10 anos ocupam, aqui, uma posição intermediária. Esta tendência geral se mostra plenamente no que diz respeito à utilização das lojas e das bibliotecas, ou ainda à prática de atividades extraescolares ${ }^{11}$. E ela intervém também, mas não totalmente,

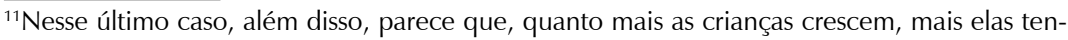
dem a praticar atividades fora da escola.
} 
na frequência aos parques e dos jardins públicos ${ }^{12}$. Diversos elementos (apreendidos durante as entrevistas com crianças) podem contribuir para explicar esse desinteresse progressivo (e relativo) das crianças por esses bairros, quando elas crescem. Primeiramente, crescendo, as crianças parecem menos dispostas a participar de atividades supervisionadas. Da mesma maneira, elas são menos propensas a acompanhar seus pais nas compras diárias. Enfim, por serem mais velhas, elas também são autorizadas, com mais frequência a se deslocarem para fora do seu bairro de residência e mais capazes de fazê-lo (eventualmente para praticar atividades extraescolares). Esta maior liberdade de deslocamento que caracteriza as crianças mais velhas é particularmente visível nos trajetos efetuados pelas crianças entre seu domicílio e sua escola: muitas crianças com idade de 11 anos realizam esse trajeto, por vezes, sozinhas, e outras vezes acompanhadas (por amigos/amigas ou por seus pais); ao contrário, uma grande proporção das crianças com idade de 9 anos faz esse trajeto sistematicamente acompanhada de seus pais.

Relações com os bairros diferenciadas segundo as configurações familiares

As crianças pesquisadas não vivem em famílias idênticas. Algumas crianças moram com seus pai e mãe, enquanto outras moram com um dos progenitores (a mãe em quase todos os casos), dispondo, por vezes, de uma segunda habitação que elas ocupam ocasionalmente (no fim de semana ou durante as férias) com o outro (pai ou mãe). Igualmente, algumas crianças não têm irmãos, enquanto outras moram com irmãos e/ ou irmãs, que podem ter mais ou menos idade do que elas. Tudo isso

\footnotetext{
${ }^{12} \mathrm{~A}$ proporção de crianças que "nunca" ou "raramente" frequentam os parques e os jardins públicos aumenta com a idade. Mas entre as crianças que utilizam os parques e os jardins públicos "muito frequentemente" ou "frequentemente", predominam as com idade de 10 anos entre as que os utilizam "muito frequentemente".
} 
intervém também nas relações que as crianças mantêm com os bairros gentrificados.

Por exemplo, as crianças que moram apenas com sua mãe têm tendência maior do que as que moram com ambos os pais a fazer um "uso fraco" ou um "uso limitado" dos bairros observados. Elas são, particularmente, muito mais numerosas entre as que não frequentam ou frequentam raramente os parques e os jardins públicos, e uma grande parcela delas não pratica atividades extraescolares fora dos estabelecimentos escolares. Por morarem só com a mãe ou só com o pai, que, muitas vezes, está pouco disponível, essas crianças de famílias monoparentais encontram, de fato, mais dificuldades em ser acompanhadas para ir ao parque ou a atividades (esportivas, artísticas, etc.). Além disso, o menor envolvimento local se explica pelos fatos de que algumas dessas crianças têm uma segunda habitação e de que, por isso, estão menos frequentemente presentes nesses bairros, especialmente no fim de semana (que constitui um momento privilegiado para a utilização dos parques). Ao mesmo tempo, por morarem com apenas um dos pais, essas crianças são menos supervisionadas no uso que fazem dos bairros gentrificados e fazem sozinhas os trajetos de seu domicílio à escola mais frequentemente do que as crianças que moram com ambos os pais.

Outro exemplo relacionado ao arranjo familiar: as crianças que moram com irmãos e/ou irmãs têm maneiras de habitar os bairros pesquisados mais desenvolvidas do que as dos filhos únicos: elas frequentam mais as lojas, as bibliotecas, os parques e os jardins públicos. Talvez seja necessário ver aqui tanto um efeito de número, que limita a mobilidade e as práticas fora do bairro de cada um dos irmãos e irmãs, quanto um efeito de grupo, em que o uso do bairro pelos irmãos e/ou irmãs pode favorecer o vínculo local dos outros irmãos/irmãs. Nesse segundo cenário, os filhos mais velhos das famílias parecem desempenhar o papel de 
"pioneiros", já que são eles, entre as crianças com irmãos e/ou irmãs, que acumulam o maior número de práticas nos bairros pesquisados. Enfim, parece também que a supervisão das práticas locais das crianças varia segundo sua posição social no interior da composição familiar: as crianças com irmãos e/ou irmãs mais velhos (que podem acompanhá-las em seus deslocamentos) são frequentemente menos monitoradas por seus pais em seus usos dos bairros gentrificados que os filhos mais velhos da família e do que os filhos únicos.

\section{Características individuais e meio social}

Essas diferenciações, individuais e familiares, são visíveis nos três bairros da pesquisa, com variações locais pouco significativas. Elas se encontram também nas três categorias que distinguimos com base do meio social das crianças, mas nesse caso com variações que podem ser significativas de um meio social a outro. Isto se aplica à diferenciação meninos/meninas no monitoramento dos usos do bairro gentrificado. Em geral, os usos pelas meninas são muito mais monitorados de que os usos pelos meninos. Mas se esta diferenciação é evidente nos grupos de crianças de classes populares e de classes médias, ela é, ao contrário, muito menos visível no grupo das crianças de classes médias-altas. Nesse grupo, tanto meninas como meninos são muito monitorados. Mais ainda, a consideração conjunta dessas duas variáveis permite observar, por exemplo, que os meninos de classes médias-altas têm usos dos bairros gentrificados mais monitorados do que as meninas de classes populares: mais da metade dos meninos de classes médias-altas são "muito fortemente" supervisionados por seus pais em seus usos do bairro, contra menos de $20 \%$ das meninas de meios populares. Em outras palavras, o monitoramento das maneiras de habitar de meninos e meninas varia significativamente segundo o meio social. 


\section{Vidas de bairro muito contrastantes}

As crianças pesquisadas têm, portanto, vidas no bairro muito contrastantes em função de seu lugar de habitação, de seu meio social, de sua idade, de seu sexo, e de sua configuração familiar. Se considerarmos essas variáveis de maneira transversal, as relações com os bairros aparecem muito estruturadas pela distância espacial com relação ao bairro gentrificado. Mas, ao mesmo tempo, os efeitos desta são consideravelmente reformulados pelas diferenciações sociais, deixando aparecer diversas categorias de crianças cujas práticas e sociabilidades são muito diversas no interior dos bairros gentrificados.

Assim, evidenciou-se que as crianças que residem no bairro gentrificado o utilizam de forma mais intensa e diversificada do que aquelas para as quais ele é o bairro da escola. Mas a distância espacial atua diferentemente sobre a relação das crianças com o bairro em função de seu meio social. Primeiramente, as crianças das classes médias-altas que moram nos bairros gentrificados são aquelas cuja vida no interior desses bairros é de longe a mais desenvolvida. Se as crianças do mesmo meio social que moram fora dos bairros gentrificados utilizam os mesmos menos intensamente que as primeiras, esse uso permanece, no entanto, suficientemente importante. Assim, para as crianças das classes médias-altas, a distância geográfica não é obstáculo e é atenuada por uma forte motorização de suas famílias, por práticas geralmente mais abertas para o conjunto da cidade, por uma comunidade de gostos, ou seja, no fim das contas, pela proximidade social.

Por outro lado, a distância espacial tem um forte impacto sobre a relação das crianças de classes populares com o bairro gentrificado e dois grupos de crianças se distinguem dentro dessa categoria. O primeiro é composto por crianças que moram fora dos bairros gentrificados: entre todas as crianças pesquisadas, são essas que atestam os usos mais fra- 
cos e os menos diversificados. Em outras palavras, para elas, a distância geográfica é consideravelmente reforçada pela distância social em relação ao bairro. Inversamente, as crianças de meios populares que residem no interior dos bairros gentrificados vivenciam esses bairros de maneira mais intensa que seus colegas do primeiro grupo, com um índice de uso próximo daquele das crianças das classes médias-altas. No seu caso, a proximidade espacial tem o efeito de atenuar a distância social. Enfim, as crianças das classes médias passam por uma categoria "intermediária": seus usos atestam relações mais distanciadas com o bairro que as duas categorias sociais precedentes, inclusive para as crianças que moram nos bairros gentrificados.

As relações das crianças com o bairro se tornam ainda mais complexas pela influência do sexo, da idade ou da configuração familiar das crianças. Por exemplo, se as crianças de meio popular que moram fora dos bairros gentrificados são muito afastadas tanto geograficamente como socialmente dos bairros gentrificados, isto é ainda mais marcado entre os meninos do que entre as meninas, e para os filhos de famílias monoparentais do que para aqueles de famílias em que ambos os pais estão presentes. Ao contrário, são as meninas das classes médias-altas que moram nos bairros gentrificados e que vivem com ambos os pais as que têm as práticas mais intensas, e ao mesmo tempo, as mais monitoradas.

Certamente, esses fortes contrastes no uso dos bairros gentrificados fazem eco às variações não menos sensíveis nas sociabilidades das crianças pesquisadas. Note-se que, neste registro, os dados quantitativos da nossa pesquisa são menos abundantes e a constituição de índices foi efetivamente mais complexa. Consequentemente, será considerado aqui somente um número limitado de dimensões da sociabilidade. No entanto, algumas tendências se desenham claramente. Em primeiro lugar, parece que a maioria das crianças pesquisadas experimenta uma mistura 
social real em suas sociabilidades, no entanto, de maneira mais acentuada no âmbito escolar do que no contexto do bairro. Em seguida, as sociabilidades e as relações com a mistura social das crianças, de maneira convergente com o que foi mostrado para os seus usos, são fortemente estruturadas simultaneamente pelas diferenciações sociais e pela distância espacial.

Para as crianças das classes médias-altas, assim como a distância espacial não é um obstáculo intransponível a seus usos, ela tem pouco efeito sobre suas sociabilidades e sua abertura (controlada) à mistura nos bairros gentrificados. Essas crianças são de fato mais abertas à mistura social na escola do que as crianças dos outros meios sociais. Fora da escola, elas têm mais tendência do que as outras crianças a ter amigos dentro e fora da escola e, ao mesmo tempo, suas sociabilidades no bairro dependem mais de uma lógica de estar entre pares. Em consequência, o fato de habitar ou não nos bairros gentrificados (socialmente mistos) pouco altera sua fraca abertura social fora da escola.

Para as crianças dos meios populares, a distância espacial tem uma forte incidência não somente sobre seus usos, mas também sobre suas sociabilidades. Assim, de modo geral e independentemente da localização de seu domicílio, essas crianças são aquelas cujas sociabilidades na escola são as mais introvertidas socialmente. Ao contrário, elas têm mais tendência do que as outras a conviver com crianças de outros meios sociais fora do estabelecimento escolar. O contraste é, portanto claro entre as crianças de meios populares que moram fora dos bairros gentrificados e aquelas que moram nesses bairros. Para as primeiras, a distância espacial reforça consideravelmente os efeitos da distância social, não somente sobre seus usos mas também sobre suas sociabilidades, acentuando o confinamento social de suas sociabilidades. Inversamente, o fato de habitar nos bairros gentrificados abre às segundas a possibilidade de desenvolver 
sociabilidades mistas ancoradas localmente, e essas sociabilidades contribuem a reforçar suas práticas no bairro gentrificado.

Quanto às sociabilidades das crianças das classes médias, elas se distinguem daquelas das duas outras categorias sociais. Como as crianças das classes médias-altas, suas sociabilidades escolares tendem à abertura social. Por outro lado, elas são menos comprometidas do que as outras, nas relações de amizade no bairro e, nesse contexto extraescolar, elas atestam uma vontade de estar entre pares mais marcada do que as crianças das duas outras categorias sociais. Sua distância social com relação ao bairro gentrificado é finalmente revelada tanto em seus usos quanto em suas sociabilidades.

Assim, a observação dos usos e das sociabilidades das crianças pesquisadas nesses bairros gentrificados revela infâncias muito diferenciadas socialmente. Isso demonstra que não existe uma "vida de bairro da criança" genérica.

\section{Conclusão}

Colocando o foco sobre as crianças, este artigo permite descobrir outras "realidades" dos bairros gentrificados e outros aspectos da gentrificação. Assim, parece que esses bairros (quando se consideram as famílias) são também lugares plenamente vivenciados pelas crianças, que residem ou não nos mesmos. Comparado com o que revela a literatura "adulta" sobre a gentrificação, parece, além disso, que as relações de coabitação que se instauram nos bairros gentrificados não são sempre marcadas pelas lógicas sociais de estar entre pares. Em Batignolles, Stoke Newington e Noe Valley, as crianças de fato praticam mais a mistura social que seus pais, e mais genericamente, que os adultos que residem em bairros gentrificados.

A observação simultânea dessas mesmas tendências em três bairros situados em três cidades e em três países diferentes permite enfatizar sua 
forte recorrência. Mas o interesse da análise comparativa conduzida nesse artigo (e do caráter transnacional da pesquisa) é mostrar também que as crianças que residem nos bairros gentrificados (ou que os frequentam) em Paris, Londres ou São Francisco, não moram e não coabitam exatamente da mesma maneira. Assim, apareceu, por exemplo, que os usos do bairro pelas crianças americanas eram frequentemente muito mais monitorados (por seus pais) do que os das crianças francesas e inglesas.

Essas diferenças não são as únicas. Dentro de cada um dos três bairros, as crianças desenvolvem maneiras variadas de viver e coabitar, em função de seu meio social e da localização de seu domicílio. Desses dois fatores, o meio social revela-se o mais determinante e a distância espacial (do domicílio à escola e ao bairro) tem um efeito mais importante sobre as relações com os bairros gentrificados para as crianças de classes populares do que para as de classes médias-altas. Mas as práticas e as sociabilidades locais das crianças dependem também, de maneira mais marcada, do meio social, de sua idade, de seu sexo e da composição familiar com irmãos/irmãs.

Enfim, nossas análises confirmam o lugar importante que ocupa o bairro na vida social das crianças. Mas, ao mesmo tempo, ao contrário de algumas questões generalizantes, fazendo do bairro o território das crianças, elas mostram que o bairro no qual elas residem não constitui o único lugar de sua vida social - quando sua escola se situa em outro bairro, que pode mais ou menos polarizar fortemente suas práticas e suas relações sociais, ou quando sua escola se situa em seu bairro de residência, quando as crianças frequentam outros lugares da cidade mais ou menos afastados de seu domicílio (para suas atividades de lazer, por exemplo).

Para aprofundar e continuar essas análises, seria pertinente estudar como essas práticas, ao mesmo tempo espaciais e sociais, atuam de maneira diferenciada na socialização das crianças, na formação social de suas maneiras de ver, de agir e de pensar (Darmon, 2010). Seria útil, também, 
observar as maneiras de morar e os efeitos socializadores dessas maneiras de morar de outras crianças que residem em outros tipos de bairros, por exemplo, em bairros populares (como a criança Richard Hoggart de 33 Newport Street), ou em bairros burgueses. Isto é o que nos propomos fazer em uma nova pesquisa que empreendemos, em Paris e em São Francisco.

Jean-Yves Authier é Professor de Sociologia, Universidade Lumière Lyon 2, Centro Max Weber.Djean-yves.authier@univlyon2.fr

Sonia Lehman-Frisch é Mestre de conferências em Geografia, Universidade de Cergy-Pontoise,MRTE. \sonia.frisch@ens.fr

\section{Referências}

1. ANANIAN, S.; BAUER, D. Les temps périscolaires. Études et résultats, n. 611. Paris: DREES, nov. 2007.

2. ASCHER, F. Metapolis ou I'avenir des villes. Paris: Odile Jacob, 1995.

3. ATKINSON, R; BRIDGE, G. (eds.). Gentrification in a Global Context. The New Urban Colonialism. Milton Park: Routledge, 2005.

4. AUTHIER, J.-Y. Les rapports au quartier. In: AUTHIER, J.-Y. (dir.). Du Domicile à la Ville: Vivre en quartier ancient. Paris: Anthropos, 2001.

5. AUTHIER, J.-Y.; BIDOU-ZACHARIASEN, C. (dir.). La gentrification urbaine. Espaces et Sociétés, n. 132-133, 2008.

6. AUTHIER, J.-Y.; LEHMAN-FRISCH, S. Le Goût des autres. Gentrification Told by Children. Urban Studies, v. 50 n. 5, 2013.

7. BALL, S. J.; VINCENT, C.; KEMP, S. Un agréable mélange d'enfants. Prise en charge de la petite enfance, mixité sociale et classes moyennes. Éducation et Sociétés, n. 14, 2004.

8. BOURDIEU, P. La Distinction. Critique sociale du jugement. Paris: Les éditions de Minuit, 1979.

9. BRIDGE, G.; DOWLING, R. Microgeographies of Retailing and Gentrification. Australian Geographer, v. 32 n. 1, 2001. 
10. BUTLER, T. Living in the Bubble. Gentrification and its "Others" in North London. Urban Studies, v. 40 n. 12, 2003.

11. BUTLER, T.; ROBSON, G. London Calling: The Middle Classes and the Remaking of Inner London. Oxford: Berg Publishers, 2003.

12. CASABIANCA, R.-M. de. Enfants sans air. Étude sociologique des enfants d'un quartier urbain. Paris, Fleurus, 1959.

13. CHAWLA, L. (dir.). Growing Up in an Urbanizing World. Londres: UNESCO, Eathscan Publications, 2002.

14. CHOMBART DE LAUWE, M.-J. (dir.). Dans la ville, des enfants. Les 6-14 ans et le pouvoir adulte : enjeux, discours, pratiques quotidiennes. Autrement, n. 10, 1977.

15. CHRISTENSEN, P.; O'BRIEN, M. (dir.). Children in the City: Home, Neighbourhood and Community. Londres: Routledge, 2003.

16. CLERVAL, A. La gentrification à Paris intra-muros. Dynamiques spatiales, rapports sociaux et politiques publiques. Thèse de doctorat en géographie. Université de Paris 1, 2008.

17. COLLET, A. Générations de classes moyennes et travail de gentrification. Changement social et changement urbain dans le Bas-Montreuil et à la CroixRousse, 1975-2005. Thèse de doctorat en sociologie. Université de Lyon 2, 2010.

18. DANIC, I.; DELALANDE ,J.; RAYOU,P. Enquêtes auprès d'enfants et de jeunes: Objets, méthodes et terrains de recherche en sciences sociales. Rennes: Presses Universitaires de Rennes, 2006.

19. DANSEREAU, F. La réanimation urbaine et la reconquête des quartiers anciens par les couches moyennes. Tour d'horizon de la littérature nord-américaine. Sociologie du Travail, v. 21, n. 2, 1985.

20. DARMON, M. La socialisation. Paris, Armand Colin, 2010.

21. DEPEAU, S. L'enfant en ville. Autonomie de déplacement et accessibilité environnementale. Thèse de doctorat en psychologie. Université de Paris 5, 2003.

22. DEPEAU, S. Radioscopie des territoires de la mobilité des enfants en milieu urbain. Comparaison entre Paris intra-muros et banlieue parisienne. Enfances, Familles, Générations, n. 8, 2008.

23. ENAUX, C.; LEGENDRE, A. Méthode d'identification des lieux investis par des enfants de six à onze ans dans leur espace de vie urbain quotidien. In: DANIC, I.; DAVID, O., DEPEAU, S. (dir.). Enfants et jeunes dans les espaces du quotidien. Rennes: Presses Universitaires de Rennes, 2010. 
24. FRÉMONT, A. La région, espace vécu. Paris: Champs Flammarion, 1976.

25. GLASS, R. Introduction. Aspects of Change, in Center for Urban Studies. In: GLASS, R. (Ed.). London. Aspects of Change. Londres: McKibbon \& Kee, 1964.

26. HART, R. Children's Experience of Place. A Developmental Study. New York: Irvington Publishers, 1979.

27. HOGGART, R. 33 Newport Street. Autobiographie d'un intellectuel issu des classes populaires anglaises. Paris: Seuil, 1991.

28. HOLLOWAY, S.; VALENTINE, G. Children's Geographies: Playing, Living, Learning. Londres, New York: Routledge, 2000.

29. KARSTEN, L. Family Gentrifyers. Challenging the City as a Place Simultaneously to Build a Career and to Raise Children. Urban Studies, v. 40, n. 12, 2003.

30. KARSTEN, L. It All Used to be Better? Different Generations on Continuity and Change in Urban Children's Daily Use of Space. Children's Geographies, v. 3, n. 3, 2005.

31. KARSTEN, L. Housing as a Way of Life. Towards an Understanding of MiddleClass Families' Preferences for an Urban Residential Location. Housing Studies, v. 22, n. 1, 2007.

32. LAREAU, A. Unequal Childhoods. Class, Race and Family Life, Berkeley. Los Angeles, Londres: University of California Press, 2003.

33. LEES, L.; SLATER, T.; WYLY, E. Gentrification. Londres, New York: Routledge, 2008.

34. LEGENDRE, A. Évolution de la connaissance et de l'utilisation des espaces publics extérieurs entre 6 et 11 ans: le cas d'Arpajon, une petite ville de la banlieue parisienne. In: DANIC, I., DAVID, O., DEPEAU, S. (dir.). Enfants et jeunes dans les espaces du quotidien. Rennes: Presses Universitaires de Rennes, 2010.

35. LEHMAN-FRISCH, S. "Like a Village". Les habitants et leur rue commerçante dans Noe Valley, un quartier gentrifié de San Francisco, Espaces et Sociétés. n. 108-109, 2002.

36. LEHMAN-FRISCH, S.; VIVET, J. Géographies des enfants et des jeunes. Carnets de géographes, n. 3, 2011.

37. LEY, D. The New Middle Class and the Remaking of the Central City. New York, Oxford University Press, 1996.

38. LYNCH, K. Growing Up in Cities. Cambridge, Massachussetts, MIT Press, 1977. 
39. MCKENDRICK, J. H.; BRADFORD, M. G.; FIELDER, A. V. Time for a party! Making Sense of the Commercialisation of leisure space for children. In: HOLLOWAY, S., VALENTINE, G., Children's Geographies: Playing, Living, Learning. Londres, New York: Routledge, 2000.

40. MCNEAL, J. Kids as Customers: A Handbook of Marketing to Children. New York: Lexington, 1992.

41. MORELLE, M. La rue des enfants, les enfants des rues. Paris: CNRS Éditions, 2007.

42. NORDSTRÖM, M. Children's Views on Child-friendly Environments in Different Geographical Cultural and Social Neighbourhoods. Urban Studies, v. 47, n. 3, 2010.

43. OBERTI, M. L'école dans la ville: Ségrégation, mixité, carte scolaire. Paris, Les Presses de Sciences Po, 2007.

44. RAMADIER, T.; DEPEAU, S. Approche méthodologique (JRS) et développementale de la représentation de l'espace quotidien de l'enfant. In: DANIC, I.; DAVID, O.; DEPEAU, S. (dir.). Enfants et jeunes dans les espaces du quotidian. Rennes: Presses universitaires de Rennes, 2010.

45. SAUTORY, O. et al. Le temps périscolaire et les contraintes professionnelles des parents. INSEE Première, n. 1370, sept., 2011.

46. SIROTA, R. (dir.). Éléments pour une sociologie de l'enfance. Rennes: Presses universitaires de Rennes, 2006.

47. TESSIER, S. (dir.). L'enfant des rues. Contribution à une socio-anthropologie de l'enfant en grande difficulté dans l'espace urbain. Paris: L'Harmattan, 2005.

48. TSOUKALA, T. Les territoires urbains de I'enfant. L'Harmattan, 2007.

49. VAlENTINE, G. Public Space and the Culture of Childhood. Ashgate, 2004.

50. VAN CRIEKINGEN, M. Réurbanisation ou gentrification? Parcours d'entrée dans la vie adulte et changements urbains à Bruxelles. Espaces et Sociétés, n. 134, 2008.

51. VAN ZANTEN, A. Choisir son école. Stratégies familiales et médiations locales. Paris: Presses universitaires de France, 2009.

52. WARD, C. The Child in the City. Londres: Architectural Press, 1978.

53. WIMER, C. et al. What Are Kids Getting Into These Days? Demographic Differences in Youth Out-of School Time Participation. Harvard Family Research Project, mar. 2006. 


\section{Anexo metodológico}

As análises e os resultados apresentados neste artigo são derivados de uma pesquisa conduzida junto a 125 crianças, 63 meninas e 62 meninos, com idades entre 9 e 11 anos. Para construir essa população, e em particular para se ter uma amostra diversificada de crianças, nós escolhemos, em cada um dos três bairros da pesquisa, uma escola pública e uma escola privada $^{13}$, e dentro de cada escola, uma classe de Curso Médio primeiro ano (CM1) ou uma classe de Curso Médio segundo ano (CM2) ou de níveis equivalentes (Year 5 em Londres, Grades 4 e 5 em São Francisco).

Quadro 1. Distribuição da amostra segundo os bairros, as escolas e as classes

\begin{tabular}{|l|l|l|l|l|l|}
\hline & \multicolumn{2}{|l|}{ Escola pública } & \multicolumn{2}{l|}{ Escola privada } & Total \\
\hline Batignolles & 27 & CM1 & 14 & CM2 & 41 \\
\hline Noe Valley & 21 & Grades 4 et 5 & 11 & Grade 4 & 32 \\
\hline Stoke Newington & 52 & Year 5 & 0 & - & 52 \\
\hline Total & 100 & & 25 & & 125 \\
\hline
\end{tabular}

Fonte: Elaborado pelos autores.

Em todos os casos, as classes selecionadas socialmente e culturalmente heterogêneas (de modo mais ou menos marcado segundo as classes e as escolas), e acolhem, ao mesmo tempo, crianças que habitam em Batignolles, Noe Valley ou Stoke Newington, e crianças que residem fora desses bairros, geralmente perto, mas também, por vezes, em outros bairros da cidade (e mesmo, em alguns casos, fora da cidade, mas não levamos em conta esses indivíduos aqui). Assim, para certas crianças, o bairro gentrificado (Batignolles, Noe Valley ou Stoke Newington) constitui

\footnotetext{
${ }^{13}$ No bairro de Stoke Newington, escolhemos uma escola pública e, na ausência de escolas privadas, uma escola confessional pública (que possibilitou ver outras estratégias escolares parentais além daquelas associadas às escolas públicas). O perfil desta última é, contudo, mais próximo do perfil das outras escolas públicas que daquele das escolas privadas.
} 
seu bairro de residência (e o bairro onde se situa sua escola), enquanto que, para outras, o bairro gentrificado corresponde ao bairro de sua escola (mas não ao seu bairro de residência).

Quadro 2. Distribuição da amostra segundo o tipo de bairro nos três bairros

\begin{tabular}{|l|l|l|l|}
\hline & Bairro de residência & Bairro de escola & Total \\
\hline Batignolles & 22 & 19 & 41 \\
\hline Noe Valley & 10 & 22 & 32 \\
\hline Stoke Newington & 28 & 24 & 52 \\
\hline Total & 60 & 65 & 125 \\
\hline
\end{tabular}

Fonte: Elaborado pelos autores.

Para compreender as relações efetivas e simbólicas mantidas por essas crianças nos três bairros gentrificados selecionados, procedemos em duas etapas. Num primeiro momento, pedimos a elas para desenhar seu bairro. Depois, realizamos entrevistas individuais, de cerca de 20 minutos, a partir de um jogo de sete fotografias dos bairros de pesquisa (delimitados por nós), no qual figuravam a biblioteca do bairro, um parque, uma rua comercial, um ponto de transporte coletivo, a outra escola pesquisada no bairro, um mercado coberto e uma praça situada no limite do bairro (substituída, em são Francisco, pela praça do centro da cidade, Union Square). Essas fotos, que as crianças eram convidadas a comentar, visavam compreender seus conhecimentos e representações do bairro, mas também recolher mais amplamente, a partir de questões associadas a cada foto, informações sobre seus usos do bairro, sobre seus deslocamentos dentro e fora do bairro, ou ainda sobre suas sociabilidades. Para completar essas informações, realizamos também entrevistas com seus professores e seus pais.

A partir das entrevistas transcritas das crianças, elaboramos uma base de dados composta, por um lado, de diversas variáveis caracterizan- 
do seus conhecimentos do bairro, suas práticas no bairro e fora dele, suas sociabilidades na escola, no bairro e na cidade etc., e por outro, diversas variáveis permitindo diferenciar as crianças segundo sua localização, sua idade, seu sexo, a composição de sua família, seu meio social etc.

Para codificar o meio social das crianças, utilizamos a classificação das profissões e categorias sociais (PCS) do Instituto Nacional da Estatística e dos Estudos Econômicos (INSEE) e distinguimos três grandes categorias: as classes médias-altas, as classes médias e as classes populares. No caso de Noe Valley e Stoke Newington, estabelecemos equivalências entre as profissões dos pais (informadas pelas escolas, retendo classicamente a profissão da pessoa de referência da família) e a nomenclatura francesa. 
Quadro 3. Distribuição da amostra segundo o meio social nos três bairros

\begin{tabular}{|c|c|c|c|c|}
\hline & Batignolles & $\begin{array}{c}\text { Stoke } \\
\text { Newington }\end{array}$ & $\begin{array}{c}\text { Noe } \\
\text { Valley }\end{array}$ & Total \\
\hline $\begin{array}{l}\text { Classes médias-altas } \\
\text { - Chefes de empresa } \\
\text { - Executivos do privado } \\
\text { - Professores, profissões científicas } \\
\text { - Profissões da informação, das artes } \\
\text { e dos espetáculos } \\
\text { - Executivos da função pública }\end{array}$ & 9 & 7 & 15 & 31 \\
\hline $\begin{array}{l}\text { Classes médias } \\
\text { - Professores das escolas, professores } \\
\text { primários e profissões similares } \\
\text { - Profissões } \\
\text { intermediárias da saúde e do trabalho social } \\
\text { - Profissões } \\
\text { intermediárias da função pública } \\
\text { - Profissões } \\
\text { intermediárias do privado } \\
\text { - Técnicos, contramestres, supervisores } \\
\text { - Artesãos, comerciantes }\end{array}$ & 15 & 12 & 9 & 36 \\
\hline $\begin{array}{l}\text { Classes populares } \\
\text { - Funcionários } \\
\text { - Trabalhadores }\end{array}$ & 17 & 26 & 8 & 51 \\
\hline Total & 41 & 45 & 32 & 118 \\
\hline
\end{tabular}

Fonte: Elaborado pelos autores. 
Sociologias, Porto Alegre, ano 19, no 46, set/dez 2017, p. 230-266

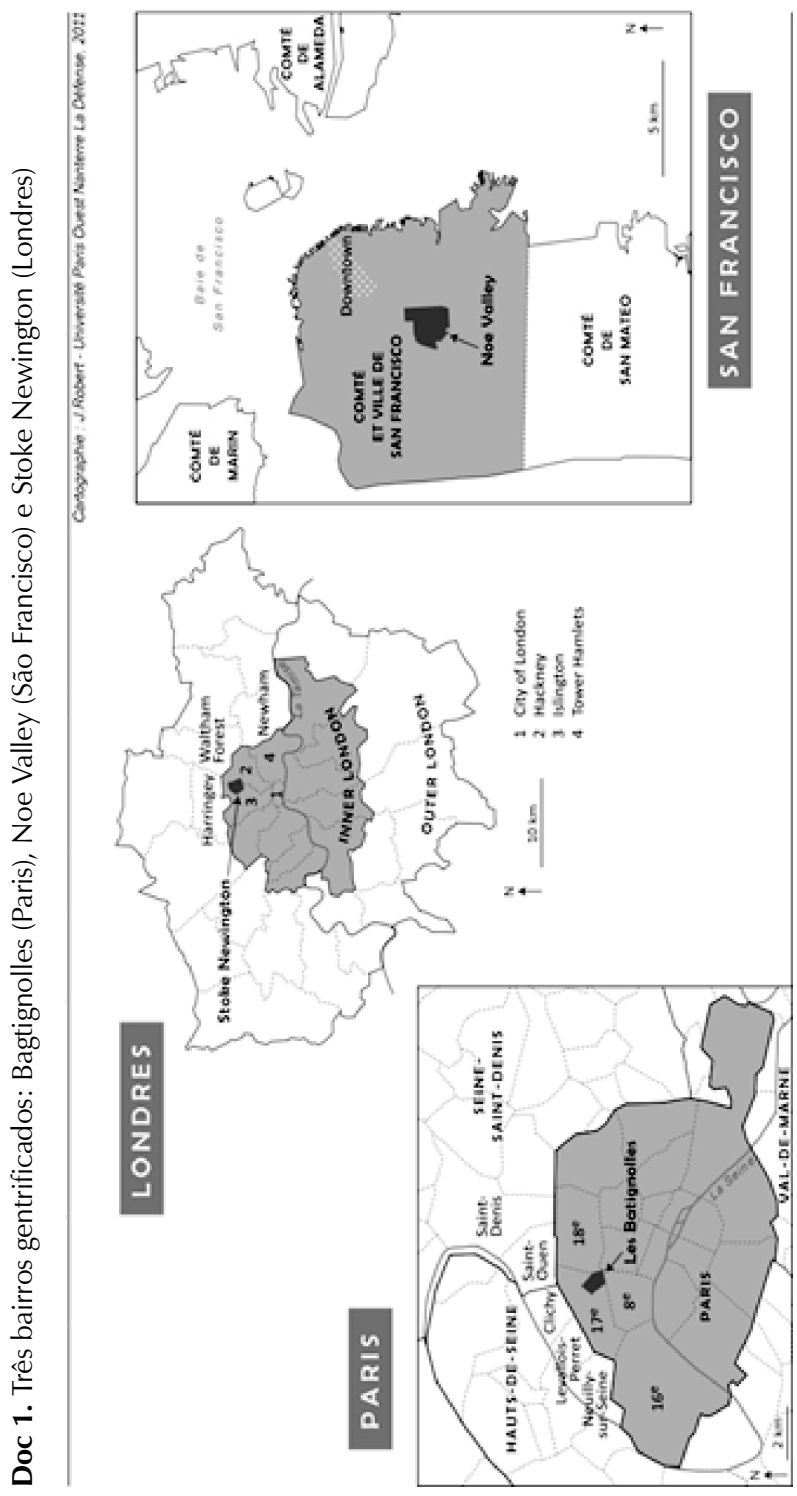

Recebido: 17.07.2015 Aceito: 26.02.2016 